\title{
CONCERNING $n$-MUTUAL APOSYNDESIS IN PRODUCTS OF CONTINUA $\left({ }^{1}\right)$
}

\author{
BY \\ LELAND E. ROGERS
}

\begin{abstract}
This paper is concerned with Cartesian products of regular Hausdorff continua and certain conditions on the factors that make the product $n$-mutually aposyndetic (given $n$ distinct points, there are $n$ disjoint subcontinua, each containing one of the points in its interior). It is proved that the product of any three regular Hausdorff continua is $n$-mutually aposyndetic for each $n \geqq 2$. Next, certain conditions on factors of products of $t w o$ continua are shown to be sufficient for the product to be $n$-mutually aposyndetic. In connection with this, the concepts of $n$-semiaposyndesis and aposyndetic-terminal points are introduced. Finally, it is proved that the product of a simple closed curve (or any other "super $n$-mutually aposyndetic" continuum) with every compact Hausdorff continuum is $n$-mutually aposyndetic for each $n \geqq 2$.
\end{abstract}

1. Introduction. The notion of $n$-mutual aposyndesis is a generalization of C. L. Hagopian's mutual aposyndesis [6], a "Hausdorff" version of F. B. Jones' aposyndesis [11]. Although $n$-mutual aposyndesis is stronger than mutual aposyndesis (for $n>2$ ), it is still weaker than local connectedness. By Theorem 5.1 of this paper, the product of three copies of the pseudo-arc [1, p. 43] is $n$-mutually aposyndetic for each $n$, but clearly not locally connected.

The study of various forms of aposyndesis in products of continua began in the 1940's when F. B. Jones [12, p. 406] (cf. [19, p. 735]) showed that the product of any two regular Hausdorff continua is aposyndetic. Almost twenty years later, E. J. Vought [18, p. 172] stated that for regular Hausdorff continua, if $M$ is $p$-aposyndetic and $N$ is $q$-aposyndetic, then $M \times N$ is $(p+q+1)$-aposyndetic. That same year, R. W. FitzGerald [4] showed that the product of any two compact Hausdorff continua is $n$-aposyndetic for each $n$. (In $\$ 5$ of this paper, we show that compactness is not necessary.) C. L. Hagopian [6] has proved that the product of any three Hausdorff continua is mutually aposyndetic, and that the product of any two aposyndetic continua is mutually aposyndetic. Finally, the author [15] showed that the product of two compact metric chainable continua is mutually aposyndetic only when each factor is an arc.

Presented in part to the Society, August 28, 1969 under the title Mutual aposyndesis in products of continua; received by the editors November 2, 1970.

AMS 1970 subject classifications. Primary 54F20; Secondary 54F25.

Key words and phrases. Aposyndetic continuum, aposyndesis, mutual aposyndesis, semiaposyndesis, terminal point, Cartesian product.

(1) This paper is part of the author's doctoral dissertation under the direction of Professor F. Burton Jones. This work was supported in part by a NASA Graduate Fellowship. 
Before the major results ( $\S \S 5,6$, and 7), we give brief discussions of $n$-semiaposyndesis (\$3) and aposyndetic-terminal points (\$4), two concepts which are useful in the study of $n$-mutual aposyndesis in products.

2. Definitions. A continuum is a nondegenerate closed connected set. The set $A$ is said to be about a point $x$ if $x \in A^{\circ}$ (interior of $A$ ). The set $A$ is said to miss a set $B$ if $A \cap B=\varnothing$. The continuum $M$ is aposyndetic at a point $x$ with respect to $a$ point $y$ (a set $A$ ) if there is a subcontinuum about $x$ missing $y(A)$. If $M$ is aposyndetic at each point with respect to each other point, then we say that $M$ is aposyndetic. For $n \geqq 1, M$ is $n$-aposyndetic if $M$ is aposyndetic at each point $x$ with respect to each $n$-point set missing $x$. If $n \geqq 2$ and $A$ is an $n$-point set in $M$, we say that $M$ is $n$-mutually aposyndetic at $A$ if there are $n$ disjoint subcontinua of $M$, each about a point of $A$. If $M$ is $n$-mutually aposyndetic at each $n$-point set, then $M$ is $n$-mutually aposyndetic. When $n=2$, we obtain the notion of mutual aposyndesis. If $n \geqq 1$ and $A$ is an $(n+1)$-point set in $M$, we say that $M$ is $n$-semiaposyndetic at $A$ if $M$ is aposyndetic at some point $x \in A$ with respect to $A-x$. If $M$ is $n$-semiaposyndetic at each $(n+1)$-point set, then $M$ is $n$-semiaposyndetic. When $n=1$, we use the term semiaposyndetic. If $n \geqq 1$ and $x$ is a point in $M$, we say that $M$ is $n$-semiaposyndetic at $x$ if for each $(n+1)$-point set $A$ containing $x, M$ is $n$-semiaposyndetic at $A$.

A subcontinuum $T$ (a point $p$ ) of the continuum $M$ is a terminal subcontinuum (terminal point) of $M[5$, p. 461] if for each pair of subcontinua $A, B$ which intersect $T$ (contain $p$ ), either $A \subset B \cup T$ or $B \subset A \cup T$ (either $A \subset B$ or $B \subset A$ ). We shall say that the point $p$ is an aposyndetic-terminal point of $M$ if for each pair of subcontinua about $p$, one contains the other.

The continuum $M$ is unicoherent if each pair of subcontinua whose union is $M$ have a connected intersection. A continuum $T$ is a triod if $T$ is the union of three proper subcontinua of $T$ such that the common part of any two of them is the common part of all three and is a proper subcontinuum (or possibly a point) of each of them. A continuum is atriodic if it contains no triod. The continuum $M$ is of type $A^{\prime}$ [17] if $M$ is irreducible between two points and there exists a monotone upper semicontinuous decomposition of $M$ onto an arc in which no element has interior.

For each point $x$ of a continuum $M, K_{x}$ denotes the set of all points $y$ such that $M$ is not aposyndetic at $x$ with respect to $y$ [12, Theorem 2]. When a product is under consideration, $\pi_{j}$ denotes the projection map onto the $j$ th factor space. The boundary and closure of a set $A$ are denoted by $\mathrm{Bd} A$ and $\mathrm{Cl} A$ respectively.

For definitions of other terms, see [14] and [20].

\section{3. $n$-semiaposyndesis.}

THEOREM 3.1. The cone over any regular Hausdorff space is n-semiaposyndetic for each $n \geqq 1$. 
Proof. Let $n$ be a positive integer and let $S$ be a regular Hausdorff space. Let $M$ be the cone over $S$, i.e., the quotient space $(S \times[0,1]) /(S \times\{0\})$. Let $p$ denote the vertex of $M$ (the point corresponding to $S \times\{0\}$ ). Let $\pi$ be the projection map from $M-p$ to $S$. Suppose $A$ is an $(n+1)$-point set in $M$. Let $D$ be the set of points in $A$ whose distance from $p$ is equal to the distance of $p$ from $A$. Let $x \in D$. Since $S$ is regular, there is an open set $U$ such that $\pi x \in U$ and $\pi(D-x) \cap \mathrm{Cl} U=\varnothing$. (If $D=\{x\}$, simply let $U=S$.) Then let $b<1$ such that $(\mathrm{Cl} U \times[0, b]) /(\mathrm{Cl} U \times\{0\})$ is a subcontinuum about $x$ missing $A-x$. Thus $M$ is $n$-semiaposyndetic at $A$ and the proof is complete.

For each $n$, the class of $n$-aposyndetic continua clearly includes those continua which are $n$-semiaposyndetic. However, the cone over the Cantor set is an example of a continuum which is $n$-semiaposyndetic for each $n$, but is not even aposyndetic. Furthermore, an $n$-aposyndetic continuum need not be $(n+1)$-semiaposyndetic:

EXAMPLE. A planar, aposyndetic continuum which is 2-semiaposyndetic at none of its points. Let $\left\{C_{\alpha}\right\}$ denote a Cantor set of concentric circles, with inner and outer circles labelled $C_{0}$ and $C_{1}$ respectively. Choose three points $a, b$, and $c$ on $C_{0}$. Let $R_{1}$ be the line segment with initial point at $a$ and last point on the circla $C_{1}$ and lying on the ray through $a$ emanating from the origin. In a similar manner, define $R_{2}$ and $R_{3}$ for $b$ and $c$ respectively. Consider the construction of the Cantor set on $[0,1]$. For each $n$, let $I_{n}$ denote the union of the $2^{n-1}$ open intervals removed at the $n$th stage of the construction. With each $R_{i}$ considered as a $[0,1]$ interval, we remove $I_{j}$ from $R_{i}$ if $j \equiv i \bmod 3$. With the $R_{i}$ 's thus modified, we let $M=\left(\bigcup R_{i}\right)$ $\cup\left(\cup C_{\alpha}\right)$. Finally we consider each of the bridging subarcs as a point, obtaining a planar continuum which is aposyndetic at each point, but not 2-semiaposyndetic at any point.

Note that in the above construction, by using 2-spheres in place of circles, and using bridging subarcs along $n+1$ rays with $I_{j}$ removed from $R_{i}$ if $j \equiv i \bmod n+1$, we obtain an example of an $(n-1)$-aposyndetic continuum in $E^{3}$ which is $n$ semiaposyndetic at none of its points.

THEOREM 3.2. Every compact semiaposyndetic atriodic continuum is either an arc or a simple closed curve.

Proof. Let $M$ be a compact semiaposyndetic atriodic continuum. By [13, p. 429] we need only show that $M$ is locally connected.

Suppose that $M$ is not connected im kleinen at a point $x$. Then there are disjoint subcontinua $C_{1}, C_{2}, \ldots$ converging to a subcontinuum $C$ which is disjoint from each $C_{i}$ and which contains $x[20$, p. 18]. Let $y \in C-x$. By semiaposyndesis, $M$ is aposyndetic at, say, $x$ with respect to $y$. Let $H$ be a subcontinuum about $x$ missing $y$. Let $C_{a}, C_{b}$, and $C_{c}$ be three of the $C_{i}$ 's which intersect $H$ but are not contained in $H$. Then $H \cup C_{a} \cup C_{b} \cup C_{c}$ is a triod, contrary to the fact that $M$ is atriodic.

THEOREM 3.3. Let $n>1$. In compact Hausdorff continua which are irreducible about $n$ points, aposyndesis and semiaposyndesis are equivalent. 
Proof. Let $M$ be irreducible about the points $p_{1}, \ldots, p_{n}$. Suppose $M$ is aposyndetic at the point $x$ with respect to the point $y$. Then there is a subcontinuum $H$ about $x$ missing $y$. For each $i \leqq n$ such that $p_{i} \notin H$, let $A_{i}$ be a subcontinuum irreducible from $p_{i}$ to $\mathrm{Bd} H$. By irreducibility, $M=\left(\cup A_{i}\right) \cup H$. Hence there is a $j$ such that $y \in A_{j}$. Since there are only a finite number of $A_{i}$ 's, $y \in A_{j}^{\circ}$. Since $x \in H^{\circ}$ and $A_{j} \cap H \subset \mathrm{Bd} H, x \notin A_{j}$. Thus $M$ is aposyndetic at $y$ with respect to $x$. (This theorem was suggested by E. D. Shirley, cf. Theorem 2 of [3, p. 116].)

THEOREM 3.4. If the semiaposyndetic compact metric continuum $M$ is irreducible between two points, then $M$ is an arc.

Proof. By Theorem 3.3, $M$ is aposyndetic. Then $M$ is an arc [19, p. 738]. (Recall that aposyndetic $\equiv$ semi-locally-connected in compact spaces $[11, \mathrm{p} .547]$.)

THEOREM 3.5. Let $n>1$. Suppose $M$ is a semiaposyndetic compact metric continuum which is irreducible about $n$ points. Then $M$ is a dendrite (a locally connected, hereditarily unicoherent compact metric continuum; also called a "tree").

Proof (Due to G. R. Gordh). Let $M$ be irreducible about the points $p_{1}, \ldots, p_{n}$. Suppose there exists a point $x \in M-\bigcup p_{i}$ which is not a weak cut point (i.e., each pair of points in $M-x$ can be joined by a continuum in $M-x)$. Then we can construct a subcontinuum $H \subset M-x$ which contains $\bigcup p_{i}$. But this is contrary to the irreducibility of $M$. Hence each point in $M-\cup p_{i}$ is a weak cut point.

By Theorem 3.3, $M$ is aposyndetic, so weak cut points are separating points (i.e., points whose complements are not connected; also called "cut points") [19, p. 737]. Hence each point in $M-\bigcup p_{i}$ is a separating point. Consequently each subcontinuum of $M$ contains uncountably many separating points of $M$. Thus $M$ is a dendrite [20, p. 88].

For other results regarding semiaposyndetic continua, particularly in the plane, see the work of C. L. Hagopian [7], [8], [9], [10]. One of his most interesting results is that semiaposyndetic continua which do not separate the plane are arcwise connected [10].

4. Aposyndetic-terminal points. This notion might be considered a "neighborhood" version of a terminal point. It is clear that every terminal point is an aposyndetic-terminal point. But the converse is not true since every point of the limiting line of the $\sin (1 / x)$-curve is an aposyndetic-terminal point while only two of those points are terminal points. However, the two notions are equivalent in a certain case as shown by the corollary to the following theorem:

THEOREM 4.1. Suppose $p$ is an aposyndetic-terminal point of the compact Hausdorff continuum $M$. Then $K_{p}$ is a terminal subcontinuum of $M$.

Proof. Since $p$ is an aposyndetic-terminal point, the collection of subcontinua about $p$ is linearly ordered by inclusion. Thus $K_{p}$, which is equal to the intersection of subcontinua about $p$, is a subcontinuum of $M$. 
To show that $K_{p}$ is terminal, let $A$ and $B$ be subcontinua of $M$ which intersect $K_{p}$. Suppose that $A \nsubseteq B \cup K_{p}$ and $B \nsubseteq A \cup K_{p}$. Then there are points $a$ and $b$ in $A-\left(B \cup K_{p}\right)$ and $B-\left(A \cup K_{p}\right)$ respectively. Since $\{a, b\} \cap K_{p}=\varnothing$, there are subcontinua $H_{a}$ and $H_{b}$ about $p$ missing $a$ and $b$ respectively, and $H=H_{a} \cap H_{b}$ is a subcontinuum about $p$ missing $\{a, b\}$. Then $H \cup A$ and $H \cup B$ are two subcontinua about $p$, neither of which contains the other. This contradicts the fact that $p$ is an aposyndetic-terminal point.

COROLlARY. If $p$ is an aposyndetic-terminal point of the regular Hausdorff continuum $M$, and $M$ is aposyndetic at $p$, then $p$ is a terminal point of $M$.

Note that in the proof of Theorem 4.1, compactness is not necessary in the event that $K_{p}=\{p\}$; thus in the corollary, $M$ need not be compact.

THEOREM 4.2. Suppose $p$ is an aposyndetic-terminal point of the compact metric continuum $M$, and $M$ is aposyndetic at $p$. Then $M$ is connected im kleinen at $p$.

Proof. Suppose that $M$ is not connected im kleinen at $p$. Then there are disjoint subcontinua $C_{1}, C_{2}, \ldots$ converging to a subcontinuum $C$ which contains $p$ and which is disjoint from each $C_{i}[20$, p. 18]. Let $q \in C-p$. By aposyndesis at $p$, there is a subcontinuum $H$ about $p$ missing $q$. Let $j$ and $k$ be distinct integers such that $C_{j}$ and $C_{k}$ intersect $H$ but are not contained in $H$. Then $H \cup C_{j}$ and $H \cup C_{k}$ are two subcontinua about $p$, neither of which is contained in the other. This is a contradiction since $p$ is an aposyndetic-terminal point.

THEOREM 4.3. Suppose $p$ is an aposyndetic-terminal point of the compact metric continuum $M$, and $K_{p}^{\circ}=\varnothing$. Then $M$ is irreducible between $p$ and some other point.

Proof. We show first that $M$ is not a triod, and secondly that $M$ is unicoherent, whereupon it will follow immediately from Theorem 3.2 of $[16$, p. 456] that $M$ is irreducible between two points.

I. $M$ is not a triod. Suppose this is not the case. Then $M$ is the union of three subcontinua $A, B$, and $C$ such that $A \cap B=A \cap C=B \cap C=A \cap B \cap C$, a proper subcontinuum (or possibly a point) of each of $A, B$, and $C$. Assume, with no loss of generality, that $A$ contains $p$. Since $A-B$ has interior, there is a point $z \in(A-B)$ $-K_{p}$. Since $z \notin K_{p}$, there is a subcontinuum $H_{z}$ about $p$ missing $z$. If $H_{z} \subset A$, then $A \cup B$ and $A \cup C$ are two subcontinua about $p$, neither of which contains the other. This contradiction implies that $H_{z} \phi A$. Hence $H_{z}$ must intersect $B$, so that $H_{z} \cup B$ is a subcontinuum. Since $B-A$ has interior, there is a point $y \in(B-A)-K_{p}$, and a subcontinuum $H_{y}$ about $p$ missing $y$. Finally, $H_{z} \cup B$ and $H_{y} \cup A$ are two subcontinua about $p$, neither of which contains the other. This contradiction implies that $M$ cannot be a triod.

II. $M$ is unicoherent. Suppose to the contrary, that there are subcontinua $A$ and $B$ such that $M=A \cup B$ and $A \cap B=C \cup D$ ( $C$ and $D$ being separated sets). 
Assume that $p \in A-B$. Then $p \in A^{\circ}$. Let $U$ and $V$ be open sets with disjoint closures about $C$ and $D$ respectively. Let $c \in C$ and $d \in D$. Let $H$ be the component of $U$ (relative to $B$ ) containing $c$, and let $K$ be the component of $V$ (relative to $B$ ) containing $d$. Then $\mathrm{Cl} H \cap \mathrm{Bd} U \cap B \neq \varnothing$ and $\mathrm{Cl} K \cap \mathrm{Bd} V \cap B \neq \varnothing$ [14, p. 18]. Hence $A \cup \mathrm{Cl} H$ and $A \cup \mathrm{Cl} K$ are two subcontinua about $p$, neither of which contains the other. This contradiction implies that $p \notin A-B$.

Similarly, $p \notin B-A$. Thus $p \in A \cap B$. Assume, without loss of generality, that $p \in C$. Since $K_{p}^{\circ}=\varnothing$, there are points $q$ and $r$ in $(A-B)-K_{p}$ and $(B-A)-K_{p}$ respectively. Let $H_{q}$ and $H_{r}$ be subcontinua about $p$ missing $q$ and $r$ respectively. Then $r \in H_{q}$ or else $H_{q} \cup A$ and $H_{q} \cup B$ contradict the fact that $p$ is an aposyndeticterminal point. Similarly, $q \in H_{r}$. But then $H_{q}$ and $H_{r}$ are two subcontinua about $p$ neither of which contains the other. This contradiction implies that $M$ is unicoherent.

Thus $M$ is irreducible between two points $r$ and $s$. Suppose that $p$ is neither of these points (otherwise the conclusion follows). One of the two points, say $r$, must be in $M-K_{p}$ since $K_{p}$ is a proper subcontinuum. Let $H$ be a subcontinuum about $p$ missing $r$. Since $p$ is an aposyndetic-terminal point, $M-H$ is connected, so that $\mathrm{Cl}(M-H)$ is a proper subcontinuum of $M$, and hence cannot contain $s$. Thus $s \in H$ for each subcontinuum about $p$; therefore $s \in K_{p}$. Suppose $L$ is a proper subcontinuum containing $r$ and $p$. Since $s \notin L$, there is an open set $U$ containing $s$ such that $U \cap L=\varnothing$. Since $K_{p}^{\circ}=\varnothing$, there is a point $z \in U-K_{p}$. Then $L \cup K_{p}$ is a subcontinuum containing $r$ and $s$ but not $z$. This contradiction implies that $M$ is irreducible from $p$ to $r$.

COROLlARY. Every compact metric aposyndetic continuum which contains an aposyndetic-terminal point is an arc.

Proof. By Theorem 4.3, the continuum is irreducible between two points. Then by Theorem 3.4, it is an arc.

Note that in Theorem 4.3 , if $K_{p}$ is allowed to have interior, the conclusion does not follow: Let $M$ be the union of two indecomposable continua and an arc (forming a triod) with the point $p$ as the intersection of those three continua. Then $p$ is an aposyndetic-terminal point, but $M$ is not irreducible between any pair of points. Note that $K_{p}$ is the union of the two indecomposable continua.

5. 3-products. This section is concerned with proving that the product of any three continua (e.g., three copies of the pseudo-arc) is $n$-mutually aposyndetic for every $n$. Thus 3 -products are related to $n$-mutual aposyndesis in somewhat the same way that 2-products are related to $n$-aposyndesis [4].

Lemma 5.1. Let $H$ and $K$ be subcontinua of the regular Hausdorff continua $M$ and $N$ respectively. Suppose $V$ and $W$ are open subsets of $H$ and $K$ respectively (proper in case $H=M$ or $K=N)$. Then $(V \times W) \cup(\mathrm{Bd} V \times K) \cup(H \times \mathrm{Bd} W)$ is a continuum in $M \times N$. 
Proof. Let $T=(\mathrm{Bd} V \times K) \cup(H \times \mathrm{Bd} W)$. Let $v \in \mathrm{Bd} V$ and $w \in \mathrm{Bd} W$. For each $z \in \mathrm{Bd} W, v \times K$ meets $H \times z$, hence $(v \times K) \cup(H \times \mathrm{Bd} W)$ is connected. Similarly, $(H \times w) \cup(\mathrm{Bd} V \times K)$ is connected. Since the point $(v, w)$ is common to these two connected sets whose union is $T, T$ is connected. Clearly $\mathrm{Bd}(V \times W) \subset T$, hence $T$ separates $M \times N$ into two parts, one of which is $V \times W$. Then $(V \times W) \cup T$ is connected $[14$, p. 25]. Since it is clearly closed, it is a continuum.

The next lemma, a 3-product version of Lemma 5.1, is the key to the proof of Theorem 5.1.

LeMma 5.2. Let $L, M$, and $N$ be regular Hausdorff continua and let $U, V$, and $W$ be proper open subsets of $L, M$, and $N$ respectively. Let $H$ denote the set

$$
\begin{aligned}
\mathrm{Cl}(U \times V \times W) & \cup(\operatorname{Bd} U \times \operatorname{Bd} V \times N) \cup(\operatorname{Bd} U \times M \times \operatorname{Bd} W) \\
& \cup(L \times \operatorname{Bd} V \times \operatorname{Bd} W) .
\end{aligned}
$$

Then $H$ is a continuum in $L \times M \times N$.

Proof. The set $H$ is clearly closed. To show that it is connected, define an operator $F_{L}$ on subsets of $L$ by $F_{L}(A)=(A \times V \times W) \cup(A \times \mathrm{Bd} V \times N) \cup(A \times M \times \mathrm{Bd} W)$. By Lemma 5.1, the set $F_{L}(p)$ is a continuum for each $p \in L$. Select points $q$, $r$, and $s$ in $\mathrm{Bd} U, \mathrm{Bd} V$, and $\mathrm{Bd} W$ respectively. The set $L \times r \times s$ is a continuum, and for each $p \in \mathrm{Bd} U$, it meets $F_{L}(p)$. Hence $F_{L}(\mathrm{Bd} U) \cup(L \times r \times s)$ is a continuum. Similarly define $F_{M}(A)=(U \times A \times W) \cup(\mathrm{Bd} U \times A \times N) \cup(L \times A \times \mathrm{Bd} W)$ and $F_{N}(A)=$ $(U \times V \times A) \cup(\mathrm{Bd} U \times M \times A) \cup(L \times \mathrm{Bd} V \times A)$, with $F_{M}$ operating on subsets of $M$ and $F_{N}$ operating on subsets of $N$. Then by arguments similar to that for $F_{L}$, we have that $F_{M}(\mathrm{Bd} V) \cup(q \times M \times s)$ and $F_{N}(\mathrm{Bd} W) \cup(q \times r \times N)$ are continua. Note that $F_{M}(\mathrm{Bd} V), F_{N}(\mathrm{Bd} W)$, and $F_{L}(\mathrm{Bd} U)$ contain $L \times r \times s, q \times M \times s$, and $q \times r \times N$ respectively. Hence $G=F_{L}(\mathrm{Bd} U) \cup F_{M}(\mathrm{Bd} V) \cup F_{N}(\mathrm{Bd} W)$ is a continuum. Next we observe that $\mathrm{Bd}(U \times V \times W) \subset G$, so $G$ separates $L \times M \times N$ into two parts, one being $U \times V \times W$. Then $(U \times V \times W) \cup G$ is connected [14, p. 25]. Finally we note that $H$ is exactly that connected set, and the proof is complete.

THEOREM 5.1. The product of any three regular Hausdorff continua is n-mutually aposyndetic for each $n \geqq 2$.

Proof. Suppose $M_{1}, M_{2}$, and $M_{3}$ are regular Hausdorff continua, and $n \geqq 2$. Let $x_{1}, \ldots, x_{n}$ be distinct points of $M_{1} \times M_{2} \times M_{3}$. There exist open sets $U(i, j)$, for $i \leqq n$ and $j \leqq 3$, satisfying the following four conditions: (1) $\pi_{j} x_{i} \in U(i, j) \subset M_{j}$; (2) if $\pi_{j} x_{i} \neq \pi_{j} x_{k}$ then $\mathrm{Cl} U(i, j) \cap \mathrm{Cl} U(k, j)=\varnothing$; (3) if $i \neq k$ and $\pi_{j} x_{i}=\pi_{j} x_{k}$, then either $\mathrm{Cl} U(i, j) \subset U(k, j)$ or $\mathrm{Cl} U(k, j) \subset U(i, j)$; (4) if $i \neq k, j \neq m, \pi_{j} x_{i}=\pi_{j} x_{k}$, and $\pi_{m} x_{i}=\pi_{m} x_{k}$, then $\mathrm{Cl} U(i, j) \subset U(k, j)$ if and only if $\mathrm{Cl} U(k, m) \subset U(i, m)$. Then for each $j \leqq n$, let

$$
\begin{aligned}
L_{j}= & \mathrm{Cl}[U(j, 1) \times U(j, 2) \times U(j, 3)] \cup\left[\mathrm{Bd} U(j, 1) \times \operatorname{Bd} U(j, 2) \times M_{3}\right] \\
& \cup\left[\operatorname{Bd} U(j, 1) \times M_{2} \times \operatorname{Bd} U(j, 3)\right] \cup\left[M_{1} \times \operatorname{Bd} U(j, 2) \times \operatorname{Bd} U(j, 3)\right] .
\end{aligned}
$$


It is clear that for each $j \leqq n, x_{j} \in L_{j}^{\circ}$ and by Lemma $5.2, L_{j}$ is a continuum. Finally, by the four properties of the $U(i, j)$ 's listed above, the $L_{j}$ 's are disjoint. Thus $M_{1} \times M_{2} \times M_{3}$ is $n$-mutually aposyndetic at $\bigcup x_{i}$.

COROLlaRY. Suppose $\mathrm{P}$ is a productive property and $\mathrm{Q}$ is a projective property such that every regular n-mutually aposyndetic continuum having property $\mathrm{P}$ must have property $\mathrm{Q}$. Then every regular Hausdorff continuum having property $\mathrm{P}$ has property $\mathrm{Q}$.

Proof. Let $M$ be a regular Hausdorff continuum having property P. Then $M^{3}$ also has property P. By Theorem 5.1, $M^{3}$ is $n$-mutually aposyndetic for each $n$. Thus $M^{3}$ must have property $\mathrm{Q}$. Since $\mathrm{Q}$ is projective, $M$ has property $\mathrm{Q}$, and the proof is complete.

Note that $\mathbf{P}$ actually need not be productive, but merely preserved under squares. Since local connectedness is a projective property, this corollary might be useful in showing that some property (perhaps 2-homogeneity; see [2, p. 77]) implies local connectedness.

Lemma 5.1 allows us to remove the compactness requirement from the hypothesis of FitzGerald's result [4]. Also needed is the following lemma which can be proved using standard techniques in the literature.

LEMMA 5.3. In regular Hausdorff spaces, countable sets are zero-dimensional.

THEOREM 5.2. The product of any two regular Hausdorff continua is countable-setaposyndetic (i.e., aposyndetic at each point $x$ with respect to each countable set $K$ such that $x \notin \mathrm{Cl} K)$.

Proof. Let $M$ and $N$ be continua, $(x, y)$ a point in $M \times N$, and $K$ a countable set in $M \times N$ such that $(x, y) \notin \mathrm{Cl} K$. Since $(x, y) \notin \mathrm{Cl} K$, there is an open set $U$ about $x$ in $M$, and an open set $V$ about $y$ in $N$ such that $\mathrm{Cl}(U \times V) \cap \mathrm{Cl} K=\varnothing$. By Lemma 5.3, we may assume that $\operatorname{Bd} U \cap \pi_{1}(K)=\varnothing$ and $\operatorname{Bd} V \cap \pi_{2}(K)=\varnothing$. Then by Lemma 5.1, $(U \times V) \cup(\mathrm{Bd} U \times N) \cup(M \times \mathrm{Bd} V)$ is the necessary subcontinuum about $(x, y)$ missing $K$.

\section{2-products.}

THEOREM 6.1. Let $n \geqq 1$. Suppose $M$ and $N$ are regular Hausdorff continua each of which is $n$-semiaposyndetic and $(n-1)$-aposyndetic. Then $M \times N$ is $(n+1)$-mutually aposyndetic.

Proof. Let $x_{1}, \ldots, x_{n+1}$ denote distinct points in $M \times N$.

Case 1. The projection of $\bigcup x_{i}$ onto at least one of the factors, say $N$, is an $(n+1)$-point set.

By $n$-semiaposyndesis, $N$ is aposyndetic at, say, $\pi_{2} x_{n+1}$ with respect to $\bigcup_{i=1}^{n} \pi_{2} x_{i}$. Let $L_{n+1}$ denote a subcontinuum of $N$ about $\pi_{2} x_{n+1}$ missing $\bigcup_{i=1}^{n} \pi_{2} x_{i}$. Let $H$ be a proper subcontinuum of $M$ about $\pi_{1} x_{n+1}$, and let $q_{1}, \ldots, q_{n}$ be distinct points of 
$M-H$. Since $N$ is $(n-1)$-aposyndetic, there are subcontinua $L_{1}, \ldots, L_{n}$ such that for each $j \leqq n, \pi_{2} x_{j} \in L_{j}^{\circ}$ and $L_{j} \cap\left(\bigcup_{i=1}^{n} \pi_{2} x_{i}-\pi_{2} x_{j}\right)=\varnothing\left[\pi_{2} x_{n+1}\right.$ may be in $\left.L_{j}\right]$. Let $W_{1}, \ldots, W_{n}$ be open sets in $M$ such that for each $j \leqq n, \pi_{2} x_{j} \in W_{j} \subset L_{j}$ and $L_{i} \cap \mathrm{Cl} W_{j}=\varnothing$ for $i \neq j$ and $i \leqq n+1$. For $j \leqq n$, define $A_{j}=\left(M \times \mathrm{Cl} W_{j}\right) \cup\left(q_{j} \times L_{j}\right)$, and define $A_{n+1}=H \times L_{n+1}$. Then $A_{1}, \ldots, A_{n+1}$ are the necessary disjoint subcontinua to show $(n+1)$-mutual aposyndesis at $\bigcup x_{\boldsymbol{i}}$.

Case 2. Each projection has at most $n$ points.

By $(n-1)$-aposyndesis, there are subcontinua $H_{1}, \ldots, H_{n+1}$ of $M$ such that for each $j \leqq n+1, \pi_{1} x_{j} \in H_{j}$ and $H_{j} \cap\left(\bigcup \pi_{1} x_{i}-\pi_{1} x_{j}\right)=\varnothing$. Similarly, in $N$ there are subcontinua $K_{1}, \ldots, K_{n+1}$ such that for each $j \leqq n+1, \pi_{2} x_{j} \in K_{j}$ and $K_{j}$ $\cap\left(\bigcup \pi_{2} x_{i}-\pi_{2} x_{j}\right)=\varnothing$. There exist open sets $U_{1}, \ldots, U_{n+1}$ in $M$ such that for each $j \leqq n+1$, (1) $\pi_{1} x_{j} \in U_{j} \subset H_{j}$, (2) if $\pi_{1} x_{i} \neq \pi_{1} x_{j}$, then $H_{i} \cap \mathrm{Cl} U_{j}=\varnothing$, and (3) if $\pi_{1} x_{j}$ $=\pi_{1} x_{k}(j \neq k)$, then $\mathrm{Bd} U_{j} \cap \mathrm{Bd} U_{k}=\varnothing$. Similarly, in $N$ there exist open sets $V_{1}, \ldots, V_{n+1}$ with analogous properties (with respect to $\pi_{2}$ and the $K_{i}$ 's). For each $j \leqq n+1$, define $A_{j}=\left(U_{j} \times V_{j}\right) \cup\left(\operatorname{Bd} U_{j} \times K_{j}\right) \cup\left(H_{j} \times \mathrm{Bd} V_{j}\right)$. By Lemma 5.1, for each $j \leqq n+1, A_{j}$ is a subcontinuum about $x_{j}$. Finally, the $A$ 's are easily seen to be disjoint. Thus the proof is complete.

Since 0 -aposyndetic means just being a continuum, we have the following strengthening of Theorem 1 of $[6$, p. 616]:

COROLLARY. The product of any two regular semiaposyndetic continua is mutually aposyndetic.

THEOREM 6.2. Suppose that each of $M$ and $N$ is a regular Hausdorff continuum with no aposyndetic-terminal point. Then $M \times N$ is mutually aposyndetic.

Proof. Let $\left(x_{1}, y_{1}\right)$ and $\left(x_{2}, y_{2}\right)$ be distinct points of $M \times N$. We may assume that $x_{1} \neq x_{2}$. We consider the following three cases:

Case 1. $y_{1}=y_{2}$.

Since $y_{1}$ is not an aposyndetic-terminal point of $N$, there exist in $N$ two subcontinua $H$ and $K$ about $y_{1}$, neither of which contains the other. Let $p$ and $q$ be points of $H-K$ and $K-H$ respectively. In $M$, let $U$ and $V$ be open sets about $x_{1}$ and $x_{2}$ respectively such that $\mathrm{Cl} U \cap \mathrm{Cl} V=\varnothing$. Then $(\mathrm{Cl} U \times H) \cup(M \times p)$ and $(\mathrm{Cl} V \times K) \cup(M \times q)$ are disjoint subcontinua about $\left(x_{1}, y_{1}\right)$ and $\left(x_{2}, y_{2}\right)$ respectively.

Case 2. $y_{1} \neq y_{2}$, and $M$ is not semiaposyndetic at $\left\{x_{1}, x_{2}\right\}$.

In $N$, let $U$ and $V$ be open sets with disjoint closures about $y_{1}$ and $y_{2}$ respectively. Since $x_{1}$ is not an aposyndetic-terminal point of $M$, there are subcontinua $H_{1}$ and $K_{1}$ about $x_{1}$, neither of which contains the other. Similarly, there are subcontinua $H_{2}$ and $K_{2}$ about $x_{2}$, neither of which contains the other. Since $M$ is not semiaposyndetic at $\left\{x_{1}, x_{2}\right\}$, both $H_{1}$ and $K_{1}$ contain $x_{2}$, and both $H_{2}$ and $K_{2}$ contain $x_{1}$.

Suppose that $H_{2} \subset H_{1}$. Then $x_{2} \in H_{1}^{\circ}$. By the choice of $H_{1}$ and $K_{1}$, there are points $p$ and $q$ in $K_{1}-H_{1}$ and $H_{1}-K_{1}$ respectively. Then the required subcontinua are 
$\left(K_{1} \times \mathrm{Cl} U\right) \cup(p \times N)$ and $\left(H_{1} \times \mathrm{Cl} V\right) \cup(q \times N)$. Similarly, if $H_{1} \subset H_{2}$, the required subcontinua exist.

So we suppose that neither $H_{1}$ nor $H_{2}$ contains the other. Let $p$ and $q$ be points in $H_{1}-H_{2}$ and $H_{2}-H_{1}$ respectively. Then the two required disjoint subcontinua are $\left(H_{1} \times \mathrm{Cl} U\right) \cup(p \times N)$ and $\left(H_{2} \times \mathrm{Cl} V\right) \cup(q \times N)$.

Case 3. $M$ is semiaposyndetic at $\left\{x_{1}, x_{2}\right\}$.

We may assume that $M$ is aposyndetic at $x_{1}$ with respect to $x_{2}$. Let $H$ be a subcontinuum of $M$ about $x_{1}$ missing $x_{2}$. Let $U$ be an open set in $M$ about $x_{2}$ such that $H \cap \mathrm{Cl} U=\varnothing$. In $N$, let $K$ be a proper subcontinuum about $y_{1}$ and let $q \in N-K$. Then $H \times K$ and $(\mathrm{Cl} U \times N) \cup(M \times q)$ are the two required subcontinua. This completes the proof of the theorem.

Since having no aposyndetic-terminal point is a very weak condition, two very ill-behaved continua can often be multiplied to obtain a mutually aposyndetic continuum. For example, let $M$ be the union of three pseudo-arcs joined together like a "triangle" to form a 3-indecomposable [2, p. 76] continuum. Then $M^{2}$ is mutually aposyndetic since $M$ has no aposyndetic-terminal point. Whether or not $M^{2}$ is 3-mutually aposyndetic is unknown to the author.

Using the theory of continua of type $A^{\prime}$ [17], we have the following corollary to Theorem 6.2:

Corollary. Suppose $M$ and $N$ are compact metric continua such that for each $x$ (in either $M$ or $N), K_{x}^{\circ}=\varnothing$. Then either $M \times N$ is mutually aposyndetic or at least one of $M$ and $N$ is of type $\mathrm{A}^{\prime}$.

Proof. Assume that $M \times N$ is not mutually aposyndetic. Then by Theorem 6.2, one of the factors, say $M$, has an aposyndetic-terminal point $p$. By Theorem 4.3, $M$ is irreducible between two points. Finally, by [17, p. 27], $M$ is of type $\mathrm{A}^{\prime}$.

THEOREM 6.3. Let $n>1$. Suppose $M$ is an (n-1)-semiaposyndetic regular Hausdorff continuum and $N$ is an $n$-mutually aposyndetic compact continuum. Then $M \times N$ is n-mutually aposyndetic.

Proof. Let $\left\{x_{1}, \ldots, x_{n}\right\}$ and $\left\{y_{1}, \ldots, y_{n}\right\}$ be $n$-point sets in $M$ and $N$ respectively. We shall construct $n^{2}$ disjoint subcontinua of $M \times N$, each about some point $\left(x_{i}, y_{j}\right)$; this will imply $n$-mutual aposyndesis of $M \times N$. Using [14, p. 18] and the $n$-mutual aposyndesis of $N$, we can construct $n$ collections of subcontinua $\{H(i, 1)\}_{i=1}^{n},\{H(i, 2)\}_{i=1}^{n}, \ldots,\{H(i, n)\}_{i=1}^{n}$ such that (1) for $i, j \leqq n, y_{j} \in H(i, j)^{\circ}$, (2) if $j \neq k$, then $\left(\bigcup_{i} H(i, j)\right) \cap\left(\bigcup_{i} H(i, k)\right)=\varnothing$, and (3) for $j, k \leqq n, H(j, k)$ $\notin \cup_{i>j} H(i, k)$. Using the $(n-1)$-semiaposyndesis of $M$, we may relabel the $x_{i}$ 's so that for each $j \leqq n, M$ is aposyndetic at $x_{j}$ with respect to $\bigcup_{i<j} x_{i}$; hence there is a subcontinuum $L_{j}$ about $x_{j}$ missing $\bigcup_{i<j} x_{i}$. Let $U_{1}, \ldots, U_{n}$ be open sets in $M$ such that for each $j \leqq n, x_{j} \in U_{j}$ and $\mathrm{Cl} U_{j} \subset L_{j}^{\circ}-\bigcup_{i>j} L_{i}$. For each pair $j, k$, choose $h_{j k} \in H(j, k)-\bigcup_{i>j} H(i, k)$. Then for each pair $j, k,\left[\mathrm{Cl} U_{j} \times H(j, k)\right] \cup\left[L_{j} \times h_{j k}\right]$ is a subcontinuum about $\left(x_{j}, y_{k}\right)$ and no two of these subcontinua intersect. Thus the theorem is established. 
For example, the product of an arc with the cone over the Cantor set is $n$ mutually aposyndetic for each $n$. However, if the semiaposyndesis is not required, the conclusion does not hold. It can easily be seen that the product of an arc with the $\sin (1 / x)$-curve is not mutually aposyndetic. In fact, the product of an arc with a chainable compact metric continuum $N$ is mutually aposyndetic if and only if $N$ is an arc [15].

7. $M \times$ everything. Certain conditions on a continuum $M$ are sufficient to insure that for every continuum $N, M \times N$ is $n$-mutually aposyndetic. The concept of an aposyndetic-terminal point proves useful in connection with one such condition.

THEOREM 7.1. Let $M$ be an aposyndetic compact metric continuum. Then $M \times N$ is mutually aposyndetic for each regular Hausdorff continuum $N$ if and only if $M$ is not an arc.

Proof. Suppose that $M \times N$ is mutually aposyndetic for each continuum $N$, and assume that $M$ is an arc. Since the product of an arc with the $\sin (1 / x)$-curve is not mutually aposyndetic [15], we have a contradiction.

Conversely, suppose that $M$ is not an arc. Then by the corollary to Theorem 4.3, $M$ has no aposyndetic-terminal point. Let $N$ be a regular Hausdorff continuum, and let $x$ and $y$ denote distinct points of $M \times N$. To show that $M \times N$ is mutually aposyndetic at $\{x, y\}$, we consider two cases:

Case 1. $\pi_{1} x \neq \pi_{1} y$.

By aposyndesis, there is a subcontinuum $H$ of $M$ about $\pi_{1} x$ missing $\pi_{1} y$. Similarly, there is a subcontinuum $K$ about $\pi_{1} y$ missing $\pi_{1} x$. Let $U$ and $V$ be open sets in $M$ such that $\pi_{1} x \in U \subset \mathrm{Cl} U \subset H-K$ and $\pi_{1} y \in V \subset \mathrm{Cl} V \subset K-H$. Finally, choose two points $p$ and $q$ in $N$. Then $(\mathrm{Cl} U \times N) \cup(H \times p)$ and $(\mathrm{Cl} V \times N) \cup(K \times q)$ are the two required disjoint subcontinua about $x$ and $y$ respectively.

Case 2. $\pi_{1} x=\pi_{1} y$.

In $N$, select open sets $U$ and $V$ with disjoint closures about $\pi_{2} x$ and $\pi_{2} y$ respectively. Since $\pi_{1} x$ is not an aposyndetic-terminal point of $M$, there are subcontinua $H$ and $K$ about $\pi_{1} x$, and points $p$ and $q$ in $H-K$ and $K-H$ respectively. Then $(H \times \mathrm{Cl} U) \cup(p \times N)$ and $(K \times \mathrm{Cl} V) \cup(q \times N)$ are the required disjoint subcontinua about $x$ and $y$ respectively. This completes the proof.

Definition. Let $n>1$. Subcontinua $H_{1}, \ldots, H_{n}$ of a continuum $M$ form a $Q$-collection for the point $x$ of $M$ if for each $j \leqq n,(1) x \in H_{j}^{\circ},(2) H_{j} \notin \bigcup_{i>j} H_{i}$, and (3) $H_{j} \notin \bigcup_{i<j} H_{i}$.

Definition. Let $n>1$. The continuum $M$ is super n-mutually aposyndetic if for each set of $n$ points $x_{1}, \ldots, x_{n}$ in $M$, there exists for each $x_{j}$, a $Q$-collection $\{H(1, j), H(2, j), \ldots, H(n, j)\}$ of $n$ subcontinua, such that if $j \neq k$,

$$
\left(\bigcup_{i=1}^{n} H(i, j)\right) \cap\left(\bigcup_{i=1}^{n} H(i, k)\right)=\varnothing .
$$

This concept is clearly stronger than $n$-mutual aposyndesis, but it does not imply local connectedness, as is seen by the product of an arc with the cone over the 
Cantor set. Conversely, there are some locally connected continua (e.g., the arc and the simple triod) which are not super $n$-mutually aposyndetic, because they have "local" terminal points.

The following lemma, which shows an interesting method for constructing subcontinua with interior in products, is the key to the proof of Theorem 7.2.

LEMMA 7.1. Let $M$ and $N$ be regular Hausdorff continua. Let $s$ and $t$ be points of a subcontinuum $H$ of $M$, and let $D$ be a subset of $N$ which separates $N$ into sets $A$ and B. Let $L=(H \times \mathrm{Cl} D) \cup(s \times A) \cup(t \times B)$. Then $L$ is a subcontinuum of $M \times N$.

Proof. It is clear that $L$ is closed. Let $f: L \rightarrow N$ denote the projection map $\pi_{2}$ restricted to $L$. Then $f$ is a monotone map since for each $y \in N, f^{-1}(y)$ is connected. Since $N$ is a continuum, $L=f^{-1}(N)$ is a continuum also.

THEOREM 7.2. Let $n>1$. Suppose $M$ is a super n-mutually aposyndetic regular continuum. Then $M \times N$ is n-mutually aposyndetic for each compact Hausdorff continuum $N$.

Proof. Suppose $\left\{x_{1}, \ldots, x_{n}\right\}$ and $\left\{y_{1}, \ldots, y_{n}\right\}$ are $n$-point sets in $M$ and $N$ respectively. For each $x_{j}$, let $H(1, j), H(2, j), \ldots, H(n, j)$ be a $Q$-collection such that if $k \leqq n$ and $k \neq j$, then $\left(\bigcup_{i} H(i, j)\right) \cap\left(\bigcup_{i} H(i, k)\right)=\varnothing$. By repeated use of Urysohn's Lemma, we can choose open sets $U_{1}, \ldots, U_{n}$ in $N$ such that for each $i \leqq n$, (1) $y_{i} \in U_{i}$, (2) if $j \neq i$, then $\mathrm{Cl} U_{i} \cap \mathrm{Cl} U_{j}=\varnothing$, (3) $N-\mathrm{Cl} U_{i}=A_{i} \cup B_{i}$, separated, (4) $\mathrm{Cl}\left(A_{i} \cup U_{i}\right) \subset A_{i+1}$, and (5) $\mathrm{Cl} B_{i+1} \subset B_{i}$. By the choice of the $H(i, j)$ 's, for each pair $j, k$, there exist points $g_{j k}$ and $h_{j k}$ in $H(j, k)-\bigcup_{i<j} H(i, k)$ and $H(j, k)-\bigcup_{i>j} H(i, k)$ respectively. By Lemma 7.1 , for each pair $j, k$, the set $\left[g_{j k} \times A_{j}\right] \cup\left[h_{j k} \times B_{j}\right] \cup\left[H(j, k) \times \mathrm{Cl} U_{j}\right]$ is a subcontinuum of $M \times N$ about the point $\left(x_{k}, y_{j}\right)$. Using properties (1)-(5) and the choice of the $g_{j k}$ 's and $h_{j k}$ 's, it can be shown that no two of the subcontinua intersect. Thus $M \times N$ is $n$-mutually aposyndetic.

COROLlaRY. The product of a simple closed curve with any compact Hausdorff continuum is n-mutually aposyndetic for each $n$.

\section{REFERENCES}

1. R. H. Bing, Concerning hereditarily indecomposable continua, Pacific J. Math. 1 (1951), 43-51. MR 13, 265.

2. C. E. Burgess, Homogeneous continua, Summary of Lectures and Seminars, Summer Institute of Set Theoretic Topology, University of Wisconsin, Madison, Wis., 1955, pp. 75-78.

3. H. S. Davis, D. P. Stadtlander and P. M. Swingle, Properties of the set function $T^{n}$, Portugal. Math. 21 (1962), 113-133. MR 25 \#5501.

4. R. W. FitzGerald, The cartesian product of non-degenerate compact continua is n-point aposyndetic, Topology Conference (Arizona State Univ., Tempe, Ariz., 1967), Arizona State University, Tempe, Ariz., 1968, pp. 324-326. MR 38 \#5155.

5. J. B. Fugate, Decomposable chainable continua, Trans. Amer. Math. Soc. 123 (1966), 460-468. MR 33 \#4906. 
6. C. L. Hagopian, Mutual aposyndesis, Proc. Amer. Math. Soc. 23 (1969), 615-622. MR 40 \#876.

7. - Concerning the cyclic connectivity of plane continua (to appear).

8. Concerning arcwise connectedness and the existence of simple closed curves in plane continua, Trans. Amer. Math. Soc. 147 (1970), 389-402. MR 40 \#8030.

9. - Arcwise-connectedness of semiaposyndetic plane continua, Trans. Amer. Math. Soc. 158 (1971), 161-165.

10. —- An arc theorem for plane continua, Illinois J. Math. (to appear).

11. F. B. Jones, Aposyndetic continua and certain boundary problems, Amer. J. Math. 63 (1941), 545-553. MR 3, 59.

12. - Concerning non-aposyndetic continua, Amer. J. Math. 70 (1948), 403-413. MR 9, 606.

13. Concerning the boundary of a complementary domain of a continuous curve, Bull. Amer. Math. Soc. 45 (1939), 428-435.

14. R. L. Moore, Foundations of point set theory, rev. ed., Amer. Math. Soc. Colloq. Publ., vol. 13, Amer. Math. Soc., Providence, R. I., 1962. MR 27 \#709.

15. L. E. Rogers, Mutually aposyndetic products of chainable continua, Pacific J. Math. (to appear).

16. R. H. Sorgenfrey, Concerning triodic continua, Amer. J. Math. 66 (1944), 439-460. MR 6, 96.

17. E. S. Thomas, Jr., Monotone decompositions of irreducible continua, Rozprawy Mat. 50 (1966), 74 pp. MR 33 \#4907.

18. E. J. Vought and F. B. Jones, Stronger forms of aposyndetic continua, Topology Conference (Arizona State Univ., Tempe, Ariz., 1967), Arizona State University, Tempe, Ariz., 1968, pp. 170-173. MR 39 \#925.

19. G. T. Whyburn, Semi-locally connected sets, Amer. J. Math. 61 (1939), 733-749. MR 1, 31. 20. —, Analytic topology, Amer. Math. Soc. Colloq. Publ., vol. 28, Amer. Math. Soc., Providence, R. I., 1942. MR 4, 86.

University of California, Riverside, California 92502

UNIVERSITY OF WYOMING, LARAMIE, WYOMING 82070 